\title{
Çocuklarda klinik olarak anlamlı üst gastrointestinal sistem kanama için risk faktörleri
}

\author{
Risk factors for clinically significant upper gastrointestinal system bleeding in children
}

(D) Yusuf AYDEMIR ${ }^{1}$, (D) Hasan Bora ULUKAPI ${ }^{2}$, (D) Zeren BARIŞ ${ }^{1}$

Eskişehir Osmangazi Universitesi Tip Fakültesi ${ }^{1}$ Çocuk Gastroenteroloji ve Hepatoloji Bilim Dall, ${ }^{2}$ Çocuk Sağllğı ve Hastalıları Anabilim Dall, Eskişehir

Giriş ve Amaç: Üst gastrointestinal sistem kanaması çocukluk çağında çogunlukla hafif olmakla birlikte, hayatı tehdit eden ciddi kanama şeklinde de görülebilmektedir. Bu çalışmada klinik olarak anlamlı üst gastrointestinal sistem kanamasına işaret eden bulguların ve risk faktörlerinin belirlenmesi amaçlandi. Gereç ve Yöntem: Çalışmaya üst gastrointestinal sistem kanaması tanısı alan, 0-18 yaş aralığında çocuklar alındı. Tanı anındaki yaşı, cinsiyeti, kanama miktarı, hematemez, melena varlı̆̆ı, başvuru anındaki yakınmaları, eşlik eden hastalıkları, kanamaya yatkınlık yaratan ilaç kullanımı, vital bulguları, kapiller dolum zamanı ve sistemik fizik muayene bulguları kaydedildi. Laboratuvar tetkiklerinden hemogram, biyokimya, koagülasyon testleri, endoskopik işlem bulguları, eritrosit transfüzyonu sayısı, uygulanan medikal ve/veya endoskopik tedaviler, acilde ya da serviste izlemleri ve kanama açısından konulan son tanısı kaydedildi. Sheffield skorlamasına göre 8 puan ve üzeri alanlar anlamlı üst gastrointestinal sistem kanaması olanlar olarak gruplandı, veriler gruplar arasında karşılaştırıldı. Bulgular: Elli beş çocuk [29 (\%52.7) kız, 26 (\% 47.3) erkek; ortalama tanı yaşı 8.4×5.4 yıl] çalışmaya alındı. Başvuru anında 22 hastada anemi, 20 hastada kan üre azotu yüksekliği, 14 hastada eritrosit sayısında düşüklük, 5 hastada hipoalbüminemi vard1. Anlamlı kanaması olan 17 hastada; melena (\%76.5 vs. \%21.1, $p<0.001$ ), solukluk (\%52.9 vs \%5.3, p <0.001), splenomegali (\%23.5 vs \%2.6, $p<0.001$ ), özofageal varis (\%23.5 vs. \%2.6, $p=0.02$ ), bolus siv1 (\%41.2 vs. \%5.3, p <0.001) ve transfüzyon gereksinimi (\%70.6 vs. \%5.3, p $<0.001)$ daha sik, kalp hizl (137.4 22.1 vs $117.5 \pm 21.3, p=0.01)$, kapiller dolum zamanı (\%35.3 vs. \%2.6, $p<0.001)$ ve kan üre azotu $(19.2 \pm 8.4 \mathrm{mg} / \mathrm{dL}$ vs $13.3 \pm 4.8 \mathrm{mg} / \mathrm{dL}, p=0.01)$ düzeyi daha yüksek, hemoglobin $(9.8 \pm 2.2 \mathrm{mg} /$ $d L$ vs $11.7 \pm 2.1 \mathrm{mg} / \mathrm{dL}, p=0.02)$, eritrosit sayls1 $\left(3.78 \times 10^{6} / \mu \mathrm{L}\right.$ vs $4.29 \times 10^{6} / \mu \mathrm{L}$ $p<0.001)$ ve albümin $(3.94 \pm 0.47$ vs $4.38 \pm 0.51, p=0.03)$ düzeyleri ise daha düşük bulundu. En sık saptanan üst gastrointestinal sistem kanaması nedenleri gastrit (\%20), Mallory Weiss (\% 16.4), özofajit (\%12.2), ülser (\%12.2) ve özofagus varisleri (\%9.1) idi. Sonuç: Ust gastrointestinal sistem kanaması olan hastanın riskini tahmin etmek ve zamanında gerekli girişimleri yapmak için anlamlı üst gastrointestinal sistem kanamasının klinik ve laboratuvar parametrelerini bilmek önemlidir. Sheffield skorlamasinda yer alan kriterlerin yanında çalışmamızda, fizik incelemede solukluk ve splenomegali, laboratuvar incelemede ise eritrosit sayısında ve albüminde düşüklük ile kan üre azotu yüksekliği anlamlı üst gastrointestinal sistem kanamaya işaret eden bulgular olarak saptanmıștır.

Anahtar kelimeler: Klinik olarak anlamlı kanama, risk faktörü, üst gastrointestinal sistem kanaması

\section{GİRIS}

Üst gastrointestinal sistem (GIS) kanamaları Trietz ligamentinin proksimalinden kaynaklanan kanamalardır. Çocukluk çağında hastaneye görece nadir başvuru nedenleri arasında olup, bir çalışmada acil başvuru sıklığı 80-90/100.000 olarak bildirilmiştir (1). Başvuruların çoğunda kanama miktarı az,
Background and Aims: Although most of the upper gastrointestinal system bleedings are self-limited, it can be life threating in a small portion of patients. The aim of this study is to determine the risk factors predicting clinically significant upper gastrointestinal system bleeding in children. Material and Method: Patients with upper gastrointestinal system bleeding and aged between 0-18 years old were enrolled. Age at diagnosis, gender, amount of bleeding, hemathemesis, melena, complaints, accompanying diseases, medication that is prone to bleeding, vital signs, capillary refill time and phsical examination findings were recorded. Hemogram, biochemistry, coagulation tests, endoscopic findings, erythrocyte transfusion, medical and/ or endoscopic treatments applied, follow-ups in emergency or service and final diagnosis of bleeding were recorded. Patients with $\geq 8$ points according to Sheffield scoring system defined as clinically significant upper gastrointestinal system bleeding and data were compared between groups. Results: Fifty five children [29 (52.7\%) girls, 26 (47.3\%) boys; mean $8.4 \pm 5.4$ years] were enrolled to the study. Seventeen children (26.8\%) had clinically significant gastrointestinal system bleeding. We detected anemia in 22 children, high blood urea nitrogen level in 20 children, low count of erythrocyte in 14 children and hypoalbuminemia in 5 children at presentation. Patients with significantly upper gastrointestinal bleeding more commonly have symptoms of melena (\%76.5 vs. \%21.1, $p<0.001$ ), pallor (\%52.9 vs \%5.3, $p<0.001$ ), splenomegaly (\%23.5 vs \%2.6, $p<0.001$ ), esophageal varice (23.5\% vs $2.6 \%, p=0.02$ ), need for a fluid bolus ( $41.2 \%$ vs $5.3 \%, p<0.001$ ), blood transfusion $(70.6 \%$ vs $5.3 \% p<0.001)$, prolonged capillary refill time (35.3\% vs $2.6 \%, p<0.001)$ and tachycardia $(137.4 \pm 22.1$ vs $117.5 \pm 21.3$, $p=0.01)$, and laboratory findings of lower erythrocyte $\left(3.78 \times 10^{6} / \mu \mathrm{L}\right.$ vs $\left.4.29 \times 10^{6} / \mu \mathrm{L}, p<0.001\right)$, hemoglobin $(9.8 \pm 2.2 \mathrm{mg} / \mathrm{dL}$ vs $11.7 \pm 2.1 \mathrm{mg} / \mathrm{dL}$, $p=0.02)$ and albumin (3.94 \pm 0.47 vs $4.38 \pm 0.51, p=0.03)$ levels with higher blood urea nitrogen $(19.2 \pm 8.4 \mathrm{mg} / \mathrm{dL}$ vs $13.3 \pm 4.8 \mathrm{mg} / \mathrm{dL}, p=0.01)$ levels. The most common final diagnosis were gastritis (20\%), Mallory Weiss tears (16.4\%), esophagitis (\% 12.2), ulcer (\%12.2) and esophageal varices (\%9.1). Conclusion: It is important to know that clinical and laboratory signs of significant upper gastrointestinal system bleeding to predict patient at risk and timely intervention. Pallor and splenomegaly, low count of erythrocyte, hypoalbuminemia and high level of blood urea nitrogen were detected as findings showing significant upper gastrointestinal system bleeding, in addition to Sheffield scoring system.

Keywords: Clinically significant bleeding, risk factor, upper gastrointestinal system bleeding

kendiliğinden sınırlanmış ve hasta klinik olarak stabil olup, hastane yatısıı gerektirmemekle birlikte tıbbi girişimlere ve aile için kaygiya neden olabilmesi açısından önemlidir. Bununla birlikte belirli bir oranda, klinik olarak anlamlı ve hemodinamiyi etkileyecek düzeyde ciddi kanama da görülebilmektedir.
İletişim: Yusuf AYDEMIR Eskişehir Osmangazi Üniversitesi Tıp Fakültesi Çocuk Gastroenteroloji ve Hepatoloji BD. Meşelik, Odunpazarı, 26480 Eskişehir, Türkiye E-mail: dryusufaydemir@yahoo.com Geliş Tarihi: 17.03.2020 Kabul Tarihi: 25.04.2020 
Üst GIS kanaması ile başvuran her hasta hemen değerlendirmeye alınmalı, bir yandan vital bulgularla birlikte fizik değerlendirmesi yapilırken bir yandan da kanama yeri, miktarı, sayısı, tekrarlayan kanama olup olmadığı, bilinen hastalıklar ve kullanılan ilaçlar sorgulanmalı ve laboratuvar değerlendirme için örnekler alınmalıdır. Üst GIS kanamasında nazogastrik sonda uygulaması aktif kanamayı göstermesi açısından olgunun durumuna göre uygulanmalıdır. Endoskopik değerlendirmenin zamanlaması ile ilgili hastanın klinik durumu ve altta yatan hastalıkları önemlidir. Erişkinlerde üst GIS kanama ciddiyetini göstermede kullanılan çok sayıda skorlama sistemi varken çocuklarda endoskopik girişim gereksinimini belirlemek için kullanılan yalnız bir skorlama sistemi bulunmaktadır (2-5).

Son yıllarda görülen yeni kanama nedenleri, gelișen tanı ve tedavi yöntemleri nedeni ile merkezimizde üst GIS kanaması tanısıyla izlenen hastaların demografik verileri, başvuru yakınmaları, laboratuvar bulguları, tanıları, tedavi rejimleri ve tedaviye yanıtlarının değerlendirilmesi ve klinik olarak anlamlı GIS kanamaya işaret eden bulguların ve risk faktörlerinin belirlenmesi amaçlandı.

\section{GEREC ve YÖNTEM}

Çalışmaya Eskişehir Osmangazi Üniversitesi Tip Fakültesi Sağlı Uygulama ve Araştırma Hastanesi'ne Ocak 2017 ve Aralık 2019 yılları arasında üst GiS kanaması ile başvuran 0-18 yaş aralığındaki çocuklar dahil edildi. ICD10 sınıflamasına göre üst GIS kanama ile ilişkili K22.6, K25.0, K25.4, K26.0, K26.4, K27.0, K27.4, K28.0, K28.4, K29.0, K92.0, K92.1 ve K92.2 tanı kodları ile hastane otomasyon sisteminden geriye dönük olarak belirtilen tarih aralı̆ı̆ında tarama yapılarak hasta verilerine ulaşıldı. Çalışma için Eskişehir Osmangazi Üniversitesi Girişimsel Olmayan Klinik Araştırmalar
Etik Kurul onayı alındı (Karar no: 17.03.2020/18). Araştırma ve yayın etiğine uyuldu.

Hastaların tanı anındaki yaşı, cinsiyeti, kanama miktarı, hematemez ve/veya melena varlı̆̆ı, başvuru anındaki yakınmaları, eşlik eden hastalıkları, kanamaya yatkınlık yaratan ilaç kullanımı, vital bulguları (nabız ve sistolik kan basıncı değerleri yaşa göre normal aralıklar göz önüne alınarak değerlendirildi), kapiller dolum zamanı ( $>2$ saniye uzamış olarak değerlendirildi) ve sistemik fizik muayene bulguları kaydedildi. Öyküden ve/veya nazogastrik sonda uygulanmışsa gelen içerik, miktar ve özellikleri kaydedildi. Laboratuvar tetkiklerinden hemogram (hemoglobin değeri, eritrosit, lökosit ve trombosit sayısı yaşa göre normal değerler göz önüne alınarak değerlendirildi), biyokimya (alanin aminotransferaz, aspartat aminotransferaz, total bilirubin, albümin, kan üre azotu, kreatinin), koagülasyon testleri (aktive parsiyel tromboplastin zamanı, protrombin zamanı ve International normalized ratio), endoskopik işlem bulguları, eritrosit transfüzyonu sayısı, bolus sıvı gereksinimi, uygulanan medikal ve/veya endoskopik tedaviler, acilde ya da serviste izlemleri ve kanama açısindan konulan son tanısı kaydedildi. Sheffield skorlamasına göre 8 puan ve üzeri alanlar anlamlı üst GíS kanama olarak gruplandırıldı (Tablo 1) (5). Veriler gruplar arasında karşılaștırıldı.

\section{İstatistiksel analiz}

Elde edilen veriler SPSS 23.0 (SPSS Inc., Chicago, IL, USA) programı ile değerlendirildi. Verilerin sayısal olanları rakamla, sıklığı yüzde ve ortalama değerleri standart sapma ile verildi. Kategorik değisskenler Ki kare testi, sürekli veriler Student t testi ve Mann-Whitney U testleri kullanılarak gruplar arasında karşılaştırıldı.

\section{Tablo 1. Sheffield skorlama sistemi}

\section{Kriter}

Öykü

Altta yatan anlamlı hastalık

Melena

Fazla miktarda hematemez

Klinik değerlendirme

Yaşa göre ortalama kalp hızının > 20 fazla olması

Uzamış kapiller dolum zamanı

Laboratuvar

Hemoglobinde $>2$ g/dL düşüş

Klinik izlem

Bolus sıvı gereksinimi

Kan transfüzyonu gereksinimi (Hemoglobin $<8$ g/dL)

Diğer kan ürünleri gereksinimi

\section{Puan}

1

1

1

1

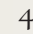

3

3

6

4

$\geq 8$ puan endoskopik girişim gereksinimini belirtir. 


\section{BULGULAR}

Üst GIS kanama ile ilgili ICD 10 tanı kodları ile hastane otomasyon sisteminden Ocak 2017 ve Aralı 2019 yllları arasinda tarama yapılarak üst GIS kanaması olan 77 çocuk saptand. Yirmi iki çocuk yeterli veri ve izlem süresi olmaması nedeni ile çalışma dışı bırakıldı. Elli beş çocuk [29 (\%52.7) kız, 26 (\%47.3) erkek; ortalama tanı yaşı 8.4 5.4 yıl] çalışmaya alındı.

Üst GIS kanaması olan 55 hastanın 34'ünde (\%61.8) yalnızca hematemez, 2'sinde (\%3.6) yalnizca melena ve 19'unda
(\%34.5) hematemez ve melena birlikte vardı. En sık eşlik eden semptomlar 23 (\%41.8) hastada karın ağrısı, 13 (\%23.6) hastada ishal ve 12 (\%21.8) hastada ateş idi. Hastaların 17'sinde (\%30.9) non-steroidal antiinflamatuvar ilaç (NSAIt) kullanımı öyküsü vardı (Tablo 2).

Hastaların 42'sine (\%76.3) nazogastrik tüp yerleştirilmiş olup, 15’i taze kan olmak üzere toplam 33'ünden kanlı içerik geleni olduğu görüldü. Öyküden öğrenilerek ya da nazogastrik sondadan gözlemlenerek toplam 34 hastada kanama miktarı fazla olarak değerlendirildi.

Tablo 2. Hastaların demografik verileri ve başvurudaki bulguları

\begin{tabular}{|c|c|c|c|c|}
\hline & $\begin{array}{l}\text { Toplam } \\
(n=55)\end{array}$ & $\begin{array}{l}\text { Klinik Anlamlı Kanama } \\
\qquad(\mathbf{n}=17)\end{array}$ & $\begin{array}{c}\text { Klinik Anlamlı } \\
\text { Olmayan Kanama }(n=38)\end{array}$ & $\begin{array}{c}\text { P } \\
\text { Değeri }\end{array}$ \\
\hline Yaş (yıl), ortalama $\pm S D$ & $8.4 \pm 5.4$ & $8.9 \pm 3.4$ & $7.5 \pm 4.2$ & 0.12 \\
\hline $\begin{array}{l}\text { Cinsiyet } \\
\text { Kız, n (\%) } \\
\text { Erkek, n (\%) }\end{array}$ & $\begin{array}{l}29(52.7) \\
26(47.3)\end{array}$ & $\begin{array}{l}9(52.9) \\
8(47.1)\end{array}$ & $\begin{array}{l}20(52.6) \\
18(47.4)\end{array}$ & 0.47 \\
\hline Hematemez, n (\%) & $53(96.3)$ & $17(100)$ & $36(94.7)$ & 0.91 \\
\hline Melena, n (\%) & $21(38.2)$ & $13(76.5)$ & $8(21.1)$ & $<0.001$ \\
\hline Kanama miktarı çokluğu & $34(61.8)$ & $10(58.8)$ & $24(63.2)$ & 0.27 \\
\hline $\begin{array}{l}\text { Eşlik eden bulgular } \\
\text { Karın ağrısı, n (\%) } \\
\text { İshal, n (\%) } \\
\text { Ateş, n (\%) }\end{array}$ & $\begin{array}{l}23(41.8) \\
13(23.6) \\
12(21.8)\end{array}$ & $\begin{array}{l}6(35.3) \\
3(17.6) \\
3(17.6)\end{array}$ & $\begin{array}{l}17(44.7) \\
10(26.3) \\
9(23.7)\end{array}$ & $\begin{array}{l}0.26 \\
0.31 \\
0.37\end{array}$ \\
\hline NSAII kullanımı, n (\%) & $17(30.9)$ & $4(23.5)$ & $13(34.2)$ & 0.02 \\
\hline GIS kanama öyküsü, n (\%) & $6(10.9)$ & $2(11.8)$ & $4(10.5)$ & 0.36 \\
\hline $\begin{array}{l}\text { Bilinen hastalıkları } \\
\text { Cerrahi öyküsü, n (\%) } \\
\text { Varis, n (\%) } \\
\text { Serebral palsi, n (\%) } \\
\text { Konjenital hepatik fibrozis, n (\%) } \\
\text { Kanama diyatezi, n (\%) } \\
\text { HSP, n (\%) } \\
\text { Lösemi/Lenfoma, n (\%) } \\
\text { PFIC tip 2, n (\%) }\end{array}$ & $\begin{array}{c}2(3.6) \\
5(9.1) \\
6(10.9) \\
1(1.8) \\
1(1.8) \\
2(3.6) \\
2(3.6) \\
1(1.8)\end{array}$ & $\begin{array}{c}2(11.8) \\
4(23.5) \\
4(23.5) \\
1(5.9) \\
1(5.9) \\
0(0) \\
1(5.9) \\
1(5.9)\end{array}$ & $\begin{array}{c}0(0) \\
1(2.6) \\
2(5.3) \\
0(0) \\
0(0) \\
2(5.3) \\
1(2.6) \\
0(0)\end{array}$ & $\begin{array}{l}0.29 \\
\mathbf{0 . 0 2} \\
0.35 \\
0.46 \\
0.46 \\
0.34 \\
0.37 \\
0.46\end{array}$ \\
\hline $\begin{array}{l}\text { Fizik muayene bulguları } \\
\text { Nabız (/dk), ortalama } \pm \text { SD } \\
\text { SKB (mmHg), ortalama } \pm \text { SD } \\
\text { Uzamış kapiller dolum zamanı, n (\%) } \\
\text { Solukluk, n (\%) } \\
\text { Batında hassasiyet, n (\%) } \\
\text { Splenomegali, n (\%) }\end{array}$ & $\begin{array}{c}122.3 \pm 18.3 \\
92.3 \pm 15.7 \\
7(12.7) \\
11(20) \\
19(34.5) \\
5(9.1)\end{array}$ & $\begin{array}{c}137.4 \pm 22.1 \\
91.6 \pm 23.8 \\
6(35.3) \\
9(52.9) \\
7(41.2) \\
4(23.5)\end{array}$ & $\begin{array}{c}117.5 \pm 21.3 \\
102.3 \pm 18.7 \\
1(2.6) \\
2(5.3) \\
12(31.6) \\
1(2.6)\end{array}$ & $\begin{array}{c}\mathbf{0 . 0 1} \\
0.21 \\
<\mathbf{0 . 0 0 1} \\
<\mathbf{0 . 0 0 1} \\
0.19 \\
<\mathbf{0 . 0 0 1}\end{array}$ \\
\hline $\begin{array}{l}\text { Tedavi } \\
\text { Bolus sıvı gereksinimi, n (\%) } \\
\text { Transfüzyon gereksinimi, n (\%) }\end{array}$ & $\begin{array}{c}9(16.4) \\
14(25.5)\end{array}$ & $\begin{array}{c}7(41.2) \\
12(70.6)\end{array}$ & $\begin{array}{l}2(5.3) \\
2(5.3)\end{array}$ & $\begin{array}{l}<0.001 \\
<0.001\end{array}$ \\
\hline
\end{tabular}

NSAII: Non-steroidal antiinflamatuvar ilaç, GIS: Gastrointestinal sistem, HSP: Henoch-Schonlein purpurası, PFIC: Progressive Familial Intrahepatic Cholestasis, SKB: Sistolik kan basınc1. 
En sık görülen fizik muayene bulguları taşikardi 41 (\%74.5) hastada, epigastrik hassasiyet 19 (\%34.5) hastada, solukluk 11 (\%20) hastada ve splenomegali 5 (\%9.1) hastada idi (Tablo 2).

Başvuru anında 22 (\%40) hastada anemi saptanmış olup, 20'sinde (\%36.4) 2 gr/dl'den fazla olmak üzere anlamlı hemoglobin düşüşü saptandı. Yirmi hastada (\%36.4) kan üre azotu yüksekliği, 14 (\%25.5) hastada eritrosit sayısında düşüklük, 5 (\%9.1) hastada hipoalbüminemi vardı (Tablo 3). Hastalardan 5'ine acil (ilk 12 saat içerisinde), 12'sine ilk 24 saatte olmak üzere 55 hastaya özofagogastroduodenoskopi yapılmış olup, tüm işlemler sonucu en sık saptanan üst GIS kanama nedenleri gastrit (\%20), Mallory Weiss (\%16.4), özofajit (\%12.2), ülser (\%12.2) ve varis (\%9.1) olarak belirlendi (Tablo 4). Endoskopik tedavi olarak özofagus varisi olan 5 hastaya bant ligasyonu $(n=5)$ ve skleroterapi $(n=3)$, kanamalı ülseri olan 3 hastaya ise hemoklips ( $\mathrm{n}=3)$ uygulandı. Yalnız melena yakınması ile başvuran 2 hastanın Meckel sintigrafi sonucu negatif olup, endoskopik değerlendirmesinde duodenal ülser saptand1.

Hastaların tümünün başvuru sırasında orali kapatılarak intravenöz proton pompa inhibitörü tedavileri yapıldı. Bolus sıvı tedavisi toplam 9 (\%16.4) hastada uygulandı. Eritrosit süspansiyonu toplam 14 (25.5) hastaya verilmiş olup, 5 hasta-

Tablo 3. Hastaların laboratuvar değerleri

\begin{tabular}{lccc} 
& $\begin{array}{c}\text { Klinik Anlamlı Kanama } \\
(\mathbf{n = 1 7})\end{array}$ & $\begin{array}{c}\text { Klinik Anlamlı Olmayan Kanama } \\
(\mathbf{n = 3 8})\end{array}$ & $\begin{array}{c}\text { P } \\
\text { Degeri }\end{array}$ \\
\hline Hemoglobin $(\mathrm{gr} / \mathrm{dL})$ & $9.8 \pm 2.2$ & $11.7 \pm 2.1$ & $\mathbf{0 . 0 2}$ \\
\hline Eritrosit $\left(\times 10^{6} / \mu \mathrm{L}\right)$ & $3.78 \pm 0.7$ & $4.29 \pm 0.9$ & $<\mathbf{0 0 1}$ \\
\hline Lökosit $\left(\times 10^{3} / \mu \mathrm{L}\right)$ & $10.81 \pm 4.17$ & $9.62 \pm 3.82$ & 0.37 \\
\hline Trombosit $\left(\times 10^{3} / \mu \mathrm{L}\right)$ & $296.7 \pm 132.6$ & $315.5 \pm 112.5$ & 0.29 \\
\hline C reaktif protein $(\mathrm{mg} / \mathrm{dL})$ & $1.6 \pm 1.1$ & $2.5 \pm 1.8$ & 0.38 \\
\hline Alanin aminotransferaz (U/L) & $24.5 \pm 14.4$ & $21.7 \pm 11.8$ & 0.54 \\
\hline Aspartat aminotransferaz (U/L) & $41.1 \pm 31.3$ & $32.4 \pm 19.7$ & 0.36 \\
\hline Total. bilirübin $(\mathrm{mg} / \mathrm{dL})$ & $0.72 \pm 0.21$ & $0.65 \pm 0.25$ & 0.56 \\
\hline Albümin $(\mathrm{gr} / \mathrm{dL})$ & $3.94 \pm 0.47$ & $4.38 \pm 0.51$ & 0.03 \\
\hline Kan üre azotu $(\mathrm{mg} / \mathrm{dL})$ & $19.2 \pm 8.4$ & $13.3 \pm 4.8$ & 0.01 \\
\hline Kreatinin $(\mathrm{mg} / \mathrm{dL})$ & $0.56 \pm 0.18$ & $0.51 \pm 0.13$ & 0.78 \\
\hline Aktive parsiyel tromboplastin zamanı & $31 \pm 2.9$ & $30 \pm 2.5$ & 0.56 \\
\hline International normalized ratio & $1.3 \pm 0.4$ & $1.1 \pm 0.3$ & 0.43 \\
\hline
\end{tabular}

Veriler ortalama \pm SD olarak sunulmuștur.

Tablo 4. Hastaların üst gastrointestinal kanama nedenleri

\begin{tabular}{|c|c|c|c|c|}
\hline Tanı & $\begin{array}{l}\text { Toplam } \\
(\mathrm{n}=55)\end{array}$ & $\begin{array}{c}\text { Klinik Anlamlı Kanama } \\
\qquad(\mathrm{n}=17)\end{array}$ & $\begin{array}{c}\text { Klinik Anlamlı } \\
\text { Olmayan Kanama }(n=38)\end{array}$ & $\begin{array}{c}\mathbf{P} \\
\text { Değeri }\end{array}$ \\
\hline Gastrit, n (\%) & $11(20)$ & $7(41.2)$ & $4(10.5)$ & 0.02 \\
\hline Mallory Weiss yırtığı, n (\%) & $9(16.4)$ & 0 & $9(23.7)$ & $<0.001$ \\
\hline Özofajit, n (\%) & $7(12.2)$ & $3(17.6)$ & $4(10.5)$ & 0.17 \\
\hline Gastrik ülser, n (\%) & $7(12.2)$ & $3(17.6)$ & $4(10.5)$ & 0.22 \\
\hline Varis, n (\%) & $5(9.1)$ & $4(23.5)$ & $1(2.6)$ & 0.02 \\
\hline Duodenal ülser, n (\%) & $5(9.1)$ & $3(17.6)$ & $2(5.3)$ & 0.11 \\
\hline Prolaps gastropati, n( \%) & $3(5.5)$ & 0 & $3(7.9)$ & 0.14 \\
\hline Eozinofilik gastroenteropati, n (\%) & $3(5.5)$ & 0 & $3(7.9)$ & 0.14 \\
\hline Inek sütü alerjisi, n (\%) & $3(5.5)$ & 0 & $3(7.9)$ & 0.14 \\
\hline Vaskülit, n (\%) & $2(3.6)$ & 0 & $2(5.3)$ & 0.24 \\
\hline
\end{tabular}


da birden fazla transfüzyon yapıldı. Hastaların 34’ü (\%61.8) yatırlarak izlendi. Progresif familyal intrahepatik kolestaz tip 2'ye bağlı son dönem karaciğer hastalığı olan bir hasta varis kanaması sunucu kaybedildi.

Hastalar Sheffield skorlamasına göre gruplandırıldığında, anlamlı kanaması olan 17 hastada daha fazla melena (\%76.5 vs. $\% 21.1, \mathrm{p}<0.001$ ), solukluk (\%52.9 vs $\% 5.3, \mathrm{p}<0.001$ ), splenomegali ( $\% 23.5$ vs $\% 2.6, \mathrm{p}<0.001)$, varis ( $\% 23.5$ vs. $\% 2.6, \mathrm{p}=0.02)$, bolus sivı (\%41.2 vs. $\% 5.3, \mathrm{p}<0.001)$ ve transfüzyon gereksinimi ( $\% 70.6$ vs. $\% 5.3, \mathrm{p}<0.001)$, daha yüksek kalp hızı $(137.4 \pm 22.1$ vs $117.5 \pm 21.3, \mathrm{p}=0.01)$, kapiller dolum zamanı (\%35.3 vs. \%2.6, p <0.001) ve kan üre azotu $(19.2 \pm 8.4 \mathrm{mg} / \mathrm{dL}$ vs $13.3 \pm 4.8 \mathrm{mg} / \mathrm{dL}, \mathrm{p}=0.01)$ düzeyi, daha düşük hemoglobin $(9.8 \pm 2.2 \mathrm{mg} / \mathrm{dL}$ vs $11.7 \pm 2.1 \mathrm{mg} /$ $\mathrm{dL}, \mathrm{p}=0.02)$, eritrosit sayls1 $\left(3.78 \times 10^{6} / \mu \mathrm{L}\right.$ vs $4.29 \times 10^{6} / \mu \mathrm{L}, \mathrm{p}$ $<0.001)$ ve albümin $(3.94 \pm 0.47$ vs $4.38 \pm 0.51, \mathrm{p}=0.03)$ düzeyi bulundu (Tablo 2 ve 3 ).

\section{TARTIŞMA}

Kanamanın yönetiminde en önemli basamak kanama ciddiyetinin belirlenmesidir. Hangi hastalarm güvenle eve gönderileceğinin, hangi hastaların yatırılarak izleneceğinin, hangi hastalara acil, hangi hastalara elektif endoskopik değerlendirme yapılacağının belirlenmesini sağlaması bakımından önemlidir. Klinik olarak anlamlı kanamayı gösteren tek bir klinik ya da laboratuvar parametresi bulunmamaktadır. Erişkinlerde kanama ciddiyetini belirlemek için kullanılan çok sayıda skorlama sistemi mevcut olup, çocuklarda ise yalnızca bir skorlama sistemi mevcuttur (2-5). Çocuklarda acil endoskopik girişim gereksinimini saptamak için geliştirilmiş Sheffield skorlama sisteminde; daha önce önemli bir hastalığın öyküsü, melena ve fazla miktarda hematemez olması, yaşa göre kalp atım hızının 20 atımdan fazla artması ve uzamış kapiller dolum zamanı, hemoglobinde $2 \mathrm{~g} / \mathrm{dl}$ 'den fazla düssme ve sıvı desteği, eritrosit transfüzyonu veya diğer kan ürünleri gereksinimi varllğına göre puanlama yapılarak ve 24 puan üzerinden 8 puan ve üzeri anlamlı kabul edilmektedir (Tablo 1) (5). Bu skorlama sistemini temel alarak çalışmamızda 17 hastada anlamlı üst GIS kanama saptadık. Literatüre göre klinik olarak anlamlı kanaması olan hasta yüzdemiz fazla idi $(6,7)$. Bunun nedeni ,3. basamak merkez olması nedeniyle hastanemize daha ciddi kanamalı hastaların yönlendirilmesine bağlandı. Avrupa Çocuk Gastroenteroloji, Hepatoloji ve Beslenme Derneği dolaşım desteği gereksinimi devam eden ve/ veya bilinen özofagus varisi olan hastalarda ilk 12 saat içinde, transfüzyon gereksinimi olan ya da hemoglobin değerinde 2 birimden fazla düşme olan hastalarda 24 saat içinde endoskopik değerlendirme yapılmasını önermektedir (8). Anlamlı üst GIS kanaması olan 17 hastamıza 5'i acil olmak üzere ilk 24 saat içerisinde özofagoduodenoskopi (ÖGD) yapıldı.
Çocukluk çağı GIS kanama etiyolojisi kanamanın yerine ve hastanın yaşına göre çeşitlilik göstermektedir (9). Önceki çalışmalarda üst GIS kanama nedeni olarak en sık Mallory Weiss bildirilmiştir (10-12). Çalışmamızda ise Mallory Weiss, gastritten sonra ikinci sıklıkta olup, klinik olarak anlamlı olmayan grupta daha sık görüldü. Başka bir çalışmada ise bizim çalışmamızda da en sık neden olarak bulunan erozif gastrite bağlı kanama oranı \%43.5 olup, bunların \%5'i anlamlı üst GIS kanama nedeni olarak bildirilmiştir (13). Çalışmamızda, anlamlı kanamaların \%35.3'ünün erozif gastrite bağlı olduğunu gördük. Diğer saptadığımız sık nedenler ise sırasıyla özofajit, gastrik ülser, varis, duodenal ülser ve son zamanlarda etiyolojide artan şekilde yer almaya başlayan eozinofilik gastroenteropati olmuştur. Varis kanaması, gelişmekte olan ülkelerde sı görülen, üst GIS kanama nedenlerindendir. Çalışmamızda l'i konjenital hepatik fibrozise, 4'ü ise kronik karaciğer hastalığına bağlı portal hipertansiyon sonucu gelişen toplam 5 özofagus varis hastası olup anlamlı üst GIS kanama grubunda daha fazla idi.

Non-steroidal anti inflamatuvar ilaçlar uygun dozlarda alınsalar bile doğrudan ya da dolaylı mukozal hasara yol açarak gastrointestinal kanama için risk oluştururlar $(14,15)$. Freedman ve ark. (7) çalışmalarında, NSAll alımı ile kanamanın ciddiyeti arasında bir ilişki bulmamışlar. Ancak çalışmamızda NSAII alımına bağlı kanamalar her iki grupta olsa da daha çok klinik olarak anlamlı olmayan kanama grubunda gözlendi. Karın ağrısı, ishal ve ateş en sık saptanan yakınmalardı. Klinik olarak anlamlı üst GIS kanama ile ilişkili bulgular solukluk ve taşikardi idi. Freedman ve ark. (7) kusma materyalinin orta veya çoğunluğunun kandan oluşmasını, Thomson ve ark. (5) ise fazla miktarda kanama olmasını anlamlı kanama açısından risk faktörü olarak bulmuşlar ancak, çalışmamızda gruplar arasında kanama miktarı açısından anlamlı fark bulamadığımız için, öyküde yol gösterici olsa da, subjektif olan bu kriter yerine daha objektif olan vital bulgular ve fizik muayene bulgularının kullanılmasının daha uygun olduğunu düşünmekteyiz. Laboratuvar değerlendirmesinde hemogram parametrelerinden hemoglobin ve eritrosit düşüklüğü, biyokimyasal parametrelerden ise albümin düşüklügü ile kan üre azotu yüksekliği anlamlı kanama ile ilişkili bulundu. Kan üre azotu kanama nedeniyle gelişen hipovolemi ve bağırsaktan fazla emilime bağlı olarak yükselir (10). Özellikle üst GIS kanamalarında daha fazla yükseldiği bilinmektedir (16). Bizim çalışmamızda ayrıca kan üre azotu yüksekliğinin kanamanın ciddiyeti ile de ilişkili olduğu görüldü. Kanama nedeniyle gelişen hipovolemide, çocuklarda sistemik vasküler direncin yüksekliği nedeniyle hipotansiyon erken dönemde görülmez. $\mathrm{Bu}$ nedenle erken dönemde saptanan taşikardi önemsenmelidir. Nabız sayısı yanında kapiller dolum zamanı ve kan basıncı değerleri ile birlikte hemodinami değerlendirilmeli ve gerektiğinde bolus sıvı ve kan transfüzyonu verilmesinde geç kalınmamalıdır. 
Hastanın riskini tahmin etmek ve zamanında gerekli girişimleri yapmak için anlamlı üst GIS kanamanın klinik ve laboratuvar parametrelerini bilmek önemlidir. Sheffield skorlamasında yer alan kanama açısından önemli hastalık, melena ve taşikardi varlığı ile hemoglobin düşüklügü ve transfüzyon ihtiyacı kriterlerinin yanında çalışmamızda fizik incelemede

\section{KAYNAKLAR}

1. Pant C, Olyaee M, Sferra TJ, Gilroy R, Almadhoun O, Deshpande A Emergency department visits for gastrointestinal bleeding in children results from the Nationwide Emergency Department Sample 20062011. Curr Med Res Opin 2015;31:347-51.

2. Enns RA, Gagnon YM, Barkun AN, et al. Validation of the Rockall scoring system for outcomes from non-variceal upper gastrointestinal bleeding in a Canadian setting. World J Gastroenterol 2006;12:7779-85.

3. Custódio Lima J, Garcia Montes C, Kibune Nagasako C, et al. Performance of the Rockall scoring system in predicting the need for intervention and outcomes in patients with nonvariceal upper gastrointestinal bleeding in a Brazilian setting: a prospective study. Digestion 2013;88:2527.

4. Bessa X, O'Callaghan E, Balleste B, et al. Applicability of the Rockall score in patients undergoing endoscopic therapy for upper gastrointestinal bleeding. Dig Liver Dis 2006;38:12-7.

5. Thomson MA, Leton N, Belsha D. Acute upper gastrointestinal bleeding in childhood: development of the Sheffield scoring system to predict need for endoscopic therapy. J Pediatr Gastroenterol Nutr 2015;60:632 6.

6. Atkinson RJ, Hurlstone DP. Usefulness of prognostic indices in upper gastrointestinal bleeding. Best Pract Res Clin Gastroenterol 2008;22:23342.

7. Freedman SB, Stewart C, RumantirM, Thull-Freedman JD. Predictors of clinically significant upper gastrointestinal hemorrhage among children with hematemesis. J Pediatr Gastroenterol Nutr 2012;54:737-43. solukluk ve splenomegali, laboratuvar incelemede ise eritrosit sayısında ve albüminde düşüklük ile kan üre azotu yüksekliği anlamlı üst GİS kanamaya işaret eden bulgular olarak saptanmiştır.

"Tüm yazarlar herhangi bir çıkar çatışması olmadığını kabul ederler."
8. Thomson M, Tringali A, Dumonceau JM, et al. Paediatric Gastrointestinal Endoscopy: European Society for Paediatric Gastroenterology Hepatology and Nutrition and European Society of Gastrointestinal Endoscopy Guidelines. J Pediatr Gastroenterol Nutr 2017;64:133-53.

9. Neidich GA, Cole SR. Gastrointestinal bleeding. Pediatr Rev 2014;35:243-53.

10. Singhi S, Jain P, Jayashree M, Lal S. Approach to a child with upper gastrointestinal bleeding. Indian J Pediatr 2013;80:326-33.

11. Chawla S, Seth D, Mahajan P, Kamat D. Upper gastrointestinal bleeding in children. Clin Pediatr 2007:46:16-21.

12. Gultekingil A, Teksam O, Gulsen HH, et al. Risk factors associated with clinically significant gastrointestinal bleeding in pediatric ED. Am J Emerg Med 2018;36:665-8.

13. Sung JJ, Tsoi KK, Ma TK, et al. Causes of mortality in patients with peptic ulcer bleeding: a prospective cohort study of 10,428 cases. Am J Gastroenterol 2010;105:84-9.

14. Kalyoncu D, Urganci N, Cetinkaya F. Etiology of upper gastrointestinal bleeding in young children. Indian J Pediatr 2009;76:899-901.

15. Berezin SH, Bostwick HE, Halata MS, et al. Gastrointestinal bleeding in children following ingestion of low-dose ibuprofen. J Pediatr Gastroenterol Nutr 2007;44:506-8

16. Felber S, Rosenthal P, Henton D. The BUN/creatinine ratio in localizing gastrointestinal bleeding in pediatric patients. J Pediatr Gastroenterol Nutr 1988;7:685-7. 